\title{
Better health reports when the grass is greener on your side of the fence? A cross-sectional study in older persons
}

\author{
Hans Bosma • Daniëlle Groffen • Marjan van den Akker • \\ Gertrudis I. J. M. Kempen · Jacques Th. M. van Eijk
}

Received: 3 November 2009/Revised: 18 June 2010/Accepted: 13 July 2010/Published online: 10 August 2010

(C) The Author(s) 2010. This article is published with open access at Springerlink.com

\begin{abstract}
Objective To study whether the luxury goods make older people feel in better health and whether this association is similar in higher and lower social classes.

Methods SMILE consists of a Dutch general population consisting of 2.637 men and women aged 60 years and older in 2007. The SF-36 was used to measure healthrelated functioning.

Results In the lower social class, having many luxury goods was related to feeling in better physical (OR 2.06, 95\% CI 1.39-3.07) and mental health (OR 1.79, 95\% CI 1.21-2.64), but not in the higher social class.

Conclusions There might be a health benefit of keeping up appearances, snobbism, and "conspicuous consumption" in older people from lower social classes.
\end{abstract}

Keywords Socioeconomic inequalities · Health · Older persons

H. Bosma $(\bowtie) \cdot$ D. Groffen · J. Th. M. van Eijk

Department of Social Medicine, CAPHRI School for Public

Health and Primary Care, Maastricht University, Maastricht, The Netherlands

e-mail: hans.bosma@socmed.unimaas.nl

M. van den Akker

Department of General Practice, CAPHRI School for Public

Health and Primary Care, Maastricht University, Maastricht,

The Netherlands

G. I. J. M. Kempen

Department of Health Care and Nursing Science, CAPHRI School for Public Health and Primary Care, Maastricht University, Maastricht, The Netherlands

\section{Introduction}

The grass is always greener on the other side of the fence is proverbially said to comfort people who negatively compare themselves to others and thereby express feelings of inadequacy and shame. Simultaneously, the proverb indicates that people tend to compare themselves to others regarding visible markers of status, standing and prestige. Prior to the recent crisis, Western countries and newly rising economies in Asia have seen huge upsurges in material prosperity (Zagha and Nankani 2005). Many people, from both higher and lower social classes, have been able to buy luxury goods. It is often assumed that this outward-directed manifestation of wealth makes people feel better and happier and might be of benefit for their health too (Groffen et al. 2008a; Pikhart et al. 2003). Scholars working in the field of socioeconomic inequalities in health have even proposed that the lack of luxury goods is as important for health as the lack of basic essential goods and they have pointed to the psychological pathways (via social comparison) contributing to the luxury goods-health association (Marmot and Wilkinson 2001). We set out to examine whether older people report better health-related functioning, when they possess many luxury goods, and to examine whether older people from low and high social classes profit equally from possessing many luxury goods.

\section{Methods}

Study population

Data were used from the Dutch longitudinal SMILE study (i.e. Study on Medical Information and Lifestyles Eindhoven), which started in November 2002 as a joint 
project of Maastricht University and the Eindhoven Corporation of Primary Health Care Centres (SGE) in the South-East of The Netherlands. Between November 2002 and May 2003, all patients in the collaborating general practices that were 55 years or older were invited to participate. Of the 5,482 participating patients (response rate $=52 \%), 2,871$ still participated in 2007 (52\%), when information on the luxury goods and health were collected and when they were 60 years old or older. The design of the present study is cross-sectional with control for prior measurements of social class as defined by income and education (measured at the baseline phase) and possession of basic goods (measured in 2004). The social class measure had 4 missing scores and the health outcome measure an additional 230, leaving 2,637 persons for the analyses (92\%). The medical ethical committee of the Maastricht Academic Hospital has approved of the study protocol of the SMILE study. More details on SMILE can be found elsewhere (van den Akker et al. 2008).

\section{Measures}

\section{Physical and mental health outcome}

Information about mental and physical functioning was derived from the Short Form Health Survey (SF-36) (Ware and Sherbourne 1992; Van der Zee et al. 1993). The 36 items and the eight sub-scales can be recoded in two higher-order components, i.e. physical and mental health-related functioning (Ware and Kosinski 2001). The best half (using the median of both variables) was used to define feeling in better physical and mental health. The median was 50.34 and 54.71 for the physical and mental outcome, respectively.

\section{Luxury goods}

Possession of luxury goods were measured asking whether or not people possessed any or more of the following 21 items: dishwasher, (tumble) dryer, solarium, microwave oven, DVD-player, DVD-recorder, video camera, PC (desktop), laptop, mp3-player, internet connection, plasma/ LCD television, cell-phone, caravan/trailer, second house, musical instrument, second car, navigation system in car, digital television, game console, and a digital photo camera (Groffen et al. 2008a, 2008b; Jehoel-Gijsbers 2003; Pikhart et al. 2003). The sum of goods was categorised into thirds using tertiles: (0-5 goods), (6-9), and (more than 9).

\section{Covariates}

Covariates were age (in years), gender, and social class. Social class was defined by using (a) education (seven ordinal categories), (b) household income (corrected for household size), and (c) a count of the possession of seven basic goods (washing machine, telephone, refrigerator, own house, car, oven, and freezer) (Groffen et al. 2008a, 2008b; Jehoel-Gijsbers 2003; Pikhart et al. 2003). These indicators were standardised $[(x-$ mean $) /$ standard deviation $]$ to make scales comparable and subsequently averaged. The result was categorised into thirds using tertiles.

\section{Statistical analyses}

Social class, physical and mental functioning, and gender were related to the number of luxury goods using crosstabulations ( $\chi^{2}$ test); analyses of variance ( $F$ test) was used to compare the mean ages across the three luxury goods categories. Logistic regression was used to estimate odds ratios of feeling in better physical and mental health for the three categories of luxury goods with the lowest third being the reference group. Age, gender, and social class were controlled for. Subsequently, the multiplicative interaction between social class and luxury goods was tested and, when the interaction appeared significant at the 0.05 level, the model was re-estimated for the three separate subgroups of social class.

\section{Results}

Fifty-eight percent of the high social class possessed more than nine luxury goods compared with $20 \%$ of the low social class $(P$ value $<0.001)$ (Table 1$)$. Men reported more luxury goods possession than women (45 vs. 34\%); those feeling in good physical and mental health and younger persons also significantly more often reported the possession of many luxury goods.

Table 2 shows that the possession of many luxury goods was related to feeling in better mental health, even when adjusted for social class. Such possession was related to a 1.62 higher odds [95\% confidence interval (CI): 1.30-2.02) of feeling in better mental health compared with possessing only few luxury goods. The association between the possession of many luxury goods and feeling in better physical health was, however, absent (OR 1.22, 95\% CI 0.97-1.53). Social class and luxury goods interacted in their association with both health outcomes; the $P$ value of the interaction term was 0.05 and 0.01 for physical and mental health, respectively (not tabulated). The pattern of odds ratios is remarkably similar for physical and mental health: the high social class did not benefit from possessing luxury goods, while the low social class strongly and significantly benefitted from possessing many luxury goods with respect to both physical and mental health. The ORs are 2.06 (95\% CI 1.39-3.07) and 1.79 (95\% CI 1.21-2.64), respectively. In terms of mental health, the middle class also benefitted from 
Table 1 Possession of luxury goods by social class, health-related functioning, gender, and age (Dutch SMILE study, 2007)

\begin{tabular}{|c|c|c|c|c|}
\hline & \multirow[t]{2}{*}{$N$} & \multicolumn{3}{|c|}{ Possession of luxury goods } \\
\hline & & $\begin{array}{l}\text { With few } \\
\text { goods }\end{array}$ & Intermediate & $\begin{array}{l}\text { With many } \\
\text { goods }\end{array}$ \\
\hline \multicolumn{5}{|c|}{ Social class $(\%)$} \\
\hline High & 879 & 16.3 & 26.3 & 57.5 \\
\hline Middle & 881 & 28.5 & 31.7 & 39.8 \\
\hline Low & 877 & 54.3 & 25.5 & 20.2 \\
\hline \multicolumn{5}{|c|}{ Physical functioning (\%) } \\
\hline Poor & 1,318 & 42.9 & 25.7 & 31.3 \\
\hline Good & 1,319 & 23.0 & 29.9 & 47.0 \\
\hline \multicolumn{5}{|c|}{ Mental functioning (\%) } \\
\hline Poor & 1,316 & 38.8 & 27.6 & 33.6 \\
\hline Good & 1,321 & 27.2 & 28.1 & 44.8 \\
\hline \multicolumn{5}{|l|}{ Gender $(\%)$} \\
\hline Men & 1,242 & 26.7 & 28.3 & 45.0 \\
\hline Women & 1,395 & 38.6 & 27.4 & 34.0 \\
\hline Age (mean) & 2,637 & 73.6 & 86.5 & 64.7 \\
\hline
\end{tabular}

All associations with luxury goods were statistically significant at the $P=0.05$ level

the possession of many luxury goods (OR $1.89,95 \%$ CI $1.31-2.75)$.

When the analyses were done separately with education, income, and basic goods (instead of the composite social class measure) or when the analyses were done with the continuous variables (using linear regression), there was a similar pattern of findings (not tabulated).

\section{Discussion}

Dutch older men and women possessing many luxury goods feel in better physical and mental health compared with their worse-off counterparts. The benefit, however, only appears apparent for those in lower social classes with lower education, lower income levels, and only few basic goods. Hence, despite on average possessing fewer luxury goods, possession of many such goods substantially increase both physical and mental health outcomes in lower social classes.

For lower social classes, luxury goods might purposefully be used to compensate for their low standing in terms of educational and income levels. In their desire for status and prestige (De Botton 2004; Marmot 2004), some might tend to camouflage and mask their lower ranking by possessing luxury goods and showing them (off) to their neighbours and others in the outside world. Our findings thus seem to support the hypothesis that there is a health benefit of keeping up appearances and snobbism. The higher social classes apparently do not benefit from luxury goods. Possibly, their higher educational and income level (and related lifestyles, behaviours, and styles of communication) already provide sufficient outward manifestation of their higher status and social ranking, so there is no or less additional value of the possession of luxury goods. While Veblen initially described the conspicuous consumption as typical for the higher social classes ("leisure class") (Veblen 2004), more recent scholars point to the possibly higher prevalence of such consumption in the poorer segments of society (Charles et al. 2007). Simultaneously, it is crude that some in lower social classes end up in poverty with severe debts, because-in their status anxiety-too many loans might be negotiated for essentially unnecessary expensive material products (European Federation of Food Banks 2009).

The results underline the importance of luxury goods for a further understanding of socioeconomic inequalities in health and how these develop. Psychosocial pathways might be important here, because the negative social comparison with others who possess more goods and who

Table 2 Odds ratios (95\% confidence interval) of better physical and mental health by possession of luxury goods, adjusted for age, gender, and social class in the total group, and adjusted for age and gender in the separate groups of social class (Dutch SMILE study, 2007)

\begin{tabular}{|c|c|c|c|c|c|c|}
\hline & $N$ & $\begin{array}{l}\% \text { better } \\
\text { health }\end{array}$ & Total group & $\begin{array}{l}\text { High social class } \\
(n=879)\end{array}$ & $\begin{array}{l}\text { Middle social class } \\
(n=881)\end{array}$ & $\begin{array}{l}\text { Low social class } \\
(n=877)\end{array}$ \\
\hline \multicolumn{7}{|c|}{ Luxury goods-physical health } \\
\hline Few goods $(0-5)$ & 870 & 34.9 & 1.00 (reference group) & 1.00 (reference group) & 1.00 (reference group) & 1.00 (reference group) \\
\hline Intermediate (6-9) & 734 & 53.8 & $1.37(1.10-1.70)$ & $1.17(0.74-1.84)$ & $1.17(0.80-1.69)$ & $1.58(1.12-2.23)$ \\
\hline Many goods (>9) & 1,033 & 60.1 & $1.22(0.97-1.53)$ & $1.04(0.67-1.62)$ & $0.85(0.58-1.24)$ & $\mathbf{2 . 0 6}(1.39-3.07)$ \\
\hline \multicolumn{7}{|c|}{ Luxury goods-mental health } \\
\hline Few goods $(0-5)$ & 870 & 41.3 & 1.00 (reference group) & 1.00 (reference group) & 1.00 (reference group) & 1.00 (reference group) \\
\hline Intermediate (6-9) & 734 & 50.5 & $1.31(1.06-1.62)$ & $0.71(0.46-1.12)$ & $1.22(0.85-1.74)$ & $\mathbf{2 . 0 0}(1.43-2.79)$ \\
\hline Many goods (>9) & 1,033 & 57.3 & $1.62(1.30-2.02)$ & $0.91(0.59-1.41)$ & $1.89(1.31-2.75)$ & $1.79(1.21-2.64)$ \\
\hline
\end{tabular}

For the high social class, the mean education was 5.48, the mean income was $1,765 €$, and the mean number of basic goods was 6.65 ; for the middle social class, the respective numbers were $3.25,1,250 €$, and 6.19 ; for the low social class, the respective numbers were $2.01,924 €$, and 5.08 
apparently better know the rules of the meritocratic rat race might result in people getting frustrated, ashamed, and depressed or hostile (Bosma 2006; De Botton 2004; Marmot 2004; Marmot and Wilkinson 2001). Some items in the luxurious goods list, such as a mobile phone and an internet connection, however, may also point to an alternative psychosocial interpretation in terms of the importance of social networks and support for health. Although the psychosocial explanation of socioeconomic inequalities in health has most often been discussed regarding the whitecollar segments of society (where deprivation is uncommon, but where health inequalities are common) (Marmot and Wilkinson 2001), the current findings suggest the additional relevance of the psychosocial pathway for the lower social classes, in particular.

Several limitations need to be discussed. Firstly, all measures were self-reported and the design was crosssectional. We should therefore acknowledge the possibility of overestimated associations and reverse causation. However, it seems somewhat awkward to assume that those with better health reports overestimated their possession of luxury goods and particularly that this happened in the lower social classes only. Another possibility that cannot be excluded is that of confounding by personality (e.g. optimism) or genetic predisposition resulting in spurious relations between luxury goods and health. But, here also, it is complicated to think about such causal (perhaps also interacting) pathways, given that these would have to be assumed to hold for the lower social classes only. As a final note, related to the self-reported health outcome, we should acknowledge the possibility that there might be a subjective health benefit only, not an "objective" health benefit. The latter possibility should be subject of further research, as is the causal pathways underlying the current cross-sectional, social class-specific findings.

Secondly, there was substantial non-response and nonrespondents more often were of lower social classes and more often reported less luxury goods and worse health. For persons not participating in 2007, the mean physical and mental health outcome in 2003 was worse (mean 44.71 and 51.17, respectively) compared with the 2003 means of the persons participating in 2007 (mean 48.02 and 52.80, respectively) ( $P$ value for the difference in means: $<0.001)$. Of the lower social classes, $42 \%$ participated in 2007 , compared with $60 \%$ of the higher social classes ( $P$ value $<0.001)$. Furthermore, $16 \%$ of the persons with few luxury goods had missing scores on the health outcome compared with $4 \%$ of the persons with many luxury goods ( $P$ value $<0.001)$. It is unclear how this pattern of nonresponse might have affected our findings and particularly its social class-specificity. Furthermore, our 2007 means for physical (46.1; $\mathrm{SD}=10.28$ ) and mental functioning (51.81; $\mathrm{SD}=9.61)$, when people were on average
74 years old, compares well to the mean of 50 and standard deviations of 10 in the general US population (Ware and Kosinski 2001). This further confirms the selectivity according to health and survival in our sample of elderly people. The findings can thus only be generalised to relatively healthy older survivors.

Thirdly, luxury goods and social class were of course related, but the Variance Inflation Factor (VIF) was smaller than 2 in the model with class and luxury goods included, which indicates the absence of bias due to multicollinearity (Kleinbaum et al. 1988). In both conceptual and empirical terms, the findings could still indicate that ranking of social class should include the dimension and measurement of luxury good possession, allowing further health differentiation at the bottom end of the socioeconomic spectrum (thereby avoiding floor effects). Similarly, as social class was measured between 2002 and 2004 and luxury goods were measured in 2007, the findings may also be interpreted in terms of a low social class-specific health benefit from upward social mobility. However, additionally controlling for income in 2006 (2007 data were not available) hardly affected the reported odds ratios (not tabulated) implying that social mobility is probably not the underlying mechanism. A final drawback of our measurement of social class concerns educational level which, as an ordinal level variable, was treated as an interval level one.

In conclusion, we may say that older men and women from lower social classes appear to benefit from possessing luxury goods. Despite lower chances of having the grass greener on their side of the fence, only lower social classes benefit from such possession. There might thus be a health benefit of keeping up appearances, snobbism, and "conspicuous consumption" in lower social classes. The higher social classes' higher education and income level and related lifestyles (manifest for the outside world) are probably already sufficient to reflect their higher position in the pecking order and the resultant health benefits thereof. Simultaneously, lower social classes should probably be better informed about the financial risks of negotiating loans for spending on unnecessary material products, particularly in times of economic crisis. Further research in this field should try to further differentiate health consequences of status inconsistency and upward social mobility, to elaborate on the concept and measurement of socioeconomic ranking, and to exclude confounding and reverse causation as much as possible.

Acknowledgments The longitudinal SMILE study is carried out by the department of General Practice of Maastricht University, in collaboration with the Eindhoven Corporation of Primary Health Care Centres. Currently, nine general practices and their 40,000 patients are participating. The investigators are indebted to the participants for their willingness to participate in the study. 
Conflict of interest The authors declare that they have no conflict of interest.

Open Access This article is distributed under the terms of the Creative Commons Attribution Noncommercial License which permits any noncommercial use, distribution, and reproduction in any medium, provided the original author(s) and source are credited.

\section{References}

Bosma H (2006) Socio-economic differences in health. Are control beliefs fundamental mediators? In: Siegrist J, Marmot M (eds) Social inequalities in health. New evidence and policy implications. Oxford University Press, Oxford

Charles KK, Hurst E, Roussanov N (2007) Conspicuous consumption and race. Working Paper 13392 (http://www.nber.org/papers/ w13392) (assessed 28 September 2009). National Bureau of Economic Research, Cambridge, MA

De Botton A (2004) Status anxiety. Hamish Hamilton, London

European Federation of Food Banks (2009) http://www.eurofood bank.org/eng/index.htm (assessed 28 September 2009)

Groffen DA, Bosma H, van den Akker M, Kempen GI, van Eijk JT (2008a) Lack of basic and luxury goods and health-related dysfunction in older persons; findings from the longitudinal SMILE study. BMC Public Health 8:242

Groffen DA, Bosma H, van den Akker M, Kempen GI, van Eijk JT (2008b) Material deprivation and health-related dysfunction in older Dutch people. Findings from the SMILE study. Eur J Public Health 18:258-263
Jehoel-Gijsbers G (2003) Sociale uitsluiting in Nederland. Netherlands Institute for Social Research/SCP, The Hague

Kleinbaum DG, Kupper LL, Muller KE (1988) Applied regression analysis and other mutlivariable methods. PWS-KENT Publishing Company, Boston

Marmot M (2004) Status syndrome. Bloomsbury, London

Marmot MG, Wilkinson RG (2001) Psychosocial and material pathways in the relation between income and health: a response to Lynch et al. Br Med J 322:1233-1236

Pikhart H, Bobak M, Rose R, Marmot M (2003) Household item ownership and self-rated health: material and psychosocial explanations. BMC Public Health 3:38

Van den Akker M, Spigt MG, De Raeve L, van Steenkiste B, Metsemakers JF, van Voorst EJ, de Vries H (2008) The SMILE study: a study of medical information and lifestyles in Eindhoven, the rationale and contents of a large prospective dynamic cohort study. BMC Public Health 8:19

Van der Zee KI, Sanderman R, Heyink J (1993) De psychometrische kwaliteiten van de MOS 36 item Short Form Health Survey in een Nederlandse populatie. Tijdschr Soc Gezondheidsz 4:183-191

Veblen T (2004) The theory of the leisure class: an economic study of institutions. Reprinted. Kessinger, Kila, MT

Ware JE, Kosinski M (2001) Interpreting SF-36 summary health measures: a response. Qual Life Res 10:415-420

Ware JE, Sherbourne CD (1992) The Rand-36 short-form health status survey 1: conceptual framework and item selection. Med Care 30:473-481

Zagha R, Nankani GT (2005) Economic growth in the 1990s. Learning from a decade of reform. World Bank, Washington, DC 